\title{
Rethinking the Concept of the Education through Digitalization of Higher Education Institutions and Blockchain
}

\author{
Ekrem Nurović ${ }^{1} \&$ Mersid Poturak $^{2}$ \\ ${ }^{1 \& 2}$ Faculty of Economics and Social Sciences, International Burch University, Sarajevo, Bosnia \& \\ Herzegovina \\ Correspondence: Ekrem Nurović, International Burch University, Sarajevo, Bosnia \& Herzegovina. \\ Email: ekrem.nurovic@gmail.com
}

Doi: $10.23918 / \mathrm{ijsses.v8i2p88}$

\begin{abstract}
E-learning has been around for the last decade, but COVID-19 has dramatically modified this concept with new dimensions. Significant changes in the educational sector are linked to new technological development and the digital transformation of the educational setting. By 2030, the world education market is expected to reach approximately USD 10 trillion. Many universities are today developing digital training strategies to speed up cloud computing, big data, IoT, and intelligent technology adoption. So here the focus is on "smart education/ Digital University". Now, most universities are implementing technologies for digital training to speed up the use of big data, cloud services, information technology, and intelligent technologies. In the future by 2040, the technology of blockchain will play an important role in university accreditation and student evidence. Learning directions will be saved and confirmed by fellow Members and universities on the blockchain. We should keep in mind that investment in education is an investment in the security of our future. The digital education strategy is the high-tech strategy, and it represents the pathways to universities to adopt the latest technologies of today's society with education quality.
\end{abstract}

Keyword: E-learning, Digitalization of Higher Education Institutions, Blockchain in Education, Future of Education

\section{Introduction}

As the corona virus spread around the globe it brought unpredictable challenges. Life that we had before had to be modified. Social distancing, avoiding crowded areas become new norms and the education system was greatly affected. Many countries needed to shut down schools and Universities. This closure affected students' academic life and more the academic environment (UNESCO, 2020). Educational institutions struggle to find a way to assist students and academic staff in moving online. This document on Education Response in Crises and Emergencies has been given special attention by international organizations. In UNESCO's Educational Framework for 2030 has been explained countries should provide alternative methods of education and training to children and teenagers who are not part of education organizations, and establish State-recognized equivalence and hybrid programs, to ensure flexible learning, both formally and informally, including in e-learning (Huang et al., 2020).

Received: April 12, 2021

Accepted: June 5, 2021

Nurović, E., \& Poturak, M. (2021). Rethinking the Concept of the Education through Digitalization of Higher Education Institutions and Blockchain. International Journal of Social Sciences \& Educational Studies, 8(2), 8895. 
Higher education institutions are under pressure from society and the state to achieve the best possible relationship between the services provided and the compensation they receive (Poturak, 2014). In social distance restriction, online learning, teaching, and professional advancements seem to be the best system (Moşteanu et al., 2020). However, even before 2020, the adoption of education, artificial intelligence, digital logic, and cybersecurity systems was already growing at an all-time high, global investment to EdTech reached $\$ 18.66$ billion in 2019 , while an online market of $\$ 350$ billion has been predicted by the year 2025. We can say that deadly Covid-19 encourages and urges the whole education system to take steps forward and adopt EdTech (Fassia et al., 2019; Mohammed et al., 2021).

\section{E-learning}

A learning system that uses the internet and the web as a basis to conduct teaching and learning is called e-Learning (Ngai, Poon, \& Chan, 2007). It can be defined as a "learning technology system that uses webbrowsers as the primary means of interaction with learners, and the internet or an intranet as the primary means of communication among its subsystems and with other systems" (cited as in (Ngai, Poon, \& Chan, 2007)). E-learning includes various forms of media which provide text, sound, photographs, animations, live streaming, and procedures such as, CD-ROM, audio or videotaping, satellite Television, computerized learning, also intranet, extranet, and online training at a local level. It emerges as the paradigm of modern education through the progress of information and communication technology development. E-learning is liberating the relationship between students and instructors, from space and time constraints to the synchronization and asynchronization model of the network training (Gayal, 2012).

Synchronous e-learning engages students in real-time online communication with the lecturer and it is done by using video calls, video conferencing, and chat rooms (Clark \& Mayer, 2003). Learning that does not require the real-time presence of students is called asynchronous e-learning. This form of learning allows maximum flexibility and students are in control of their time but lack instant feedback. (Snart, 2010). This type of learning is usually done by using learning management systems such as Moodle (Rice, 2011).

E-learning is generally synonymous with educational technology, including digital learning, technology improved learning (TEL), computer-based instruction, and computer-managed education as primary components, both SI (MKS) and the CGS. In general, electronic learning is consistent with the technology of education. The LIS e-learner blogs and wikis thus emphasize the use of digital multimedia and resources such as discussion boards, wiki, Podcasts, and second-level virtual worlds like LITA (Kannadhasan et al., 2020).

Since Web 2.0 was launched, e-learning has gradually been expanding with websites like Udemy, Udacity, Coursera, Edx, Khan Academy, and FutureLearn growing year after year from 2015. While virtual education or e-learning may be advantageous for many, it can be difficult for others (Reed, 2021). Since the resurgence of technology-based learning, e-learning environments have received considerable attention. Nearly all education programs have incorporated ICT to a certain extent. This creates e-learning environments for students to interact with other students, teachers, and genuine learning resources (Norman et al., 2013). 


\section{Changing Ecology of Education}

The global education system is currently undergoing significant changes in the field of new technology development and the digital transformation of education. Education becomes massive and at the same time personalized. According to Holon IQ, the international intelligence education market, "crowding in the population will be a key educational challenge. By 2035, the world's student population is estimated to be 2.7 billion," with just over 500 million now. Asian and African countries, where nearly $90 \%$ of the population under 30 years of age reside, will be increasing in number. Digital technologies will be used in professional training. By 2030, the global education market is expected to reach around US\$10 trillion. The proportion of compulsory education expenses for 12 years is US\$ 5.5 trillion, while higher education costs US\$ 2.5 trillion. (Spies \& Brothers, 2020).

Many universities, both at undergraduate and post-graduate levels, have included online courses in their academic offer. The world's e-learning sector continues to grow around 35.6 billion dollars were invested in the world in 2011. The statistic reached more than $\$ 107$ billion in 2013 and $\$ 56.2$ billion at the end of 2015. Universities only have a small market share. What is even more significant is the statistics that half of all university students study at least one online course at a time. E-learning is based on conventional university teaching for different reasons because it is more cost-effective but also because it could be more effective in terms of knowledge acquired during the learning experience. At least that is what some studies declare that reliability of data can be enhanced by approximately 60\% (Pappas, 2020).

In a UK report, it was stated that it was the job of CIOs across the country to enable the sector to provide learning via the Internet and that this was a Hercules task for several IT universities and colleges. Wherever universities had been on their digital journey before recent months, the resulting shift into distant and hybrid education has made the field in the higher education industry more equal. In the United Kingdom, Microsoft recently partnered with Ucisa, the digital education practitioners' professional body leading the way in an extensive quality interview with 14 CIOs and IT leaders at universities throughout England, Wales, Scotland, and Northern Ireland to gain insights and insights into the digital future of the education. The UK Universities say that higher education institutions generate $£ 95$ billion for the UK economy, as do international students and visitors. This includes revenue raised through business relationships, research, and resources spent by local students and staff. Consequently, it is vital to achieving the right digital platforms to ensure a hybrid supply model.

\section{Digitalization of Education}

Kargic and Poturak, (2014) investigated in their study what factors are students most influenced by when deciding on university type choice? Digitalization plays a very important role. In society's development, digitization is becoming a global trend. New digital technology was developed in the era of Web 3.0 and also the "Industry 4.0" which is the fourth industrial revolution. The system of education is affected by the development of different mobile apps, the resurgence of IoT devices, 3D printers, robotic systems, and the ability to process large quantities of information. Artificial Intelligence, robotic systems, additive technological popularity, biotechnology, nanotechnology, and much else are essential parts of modern life. Many universities currently are implementing technologies for digital training to speed up the use of big 
data, cloud services, information technology, and intelligent technologies (Budur et al., 2020). They mainly focus on "smart education" (Dzhavdatovna \& Azimovich, 2020).

The digital learning technologies allow students to monitor how well they have perfected new skills and knowledge, to quickly correct the educational process; (Rudich, 2020). An advantage of digital education technology is the possibility of personalized education. Currently, trainees prefer a set of high-quality professional skills individually. Concerning the big one, today's youth have already acquired a Digital personality, says Ed Clark, Supervisor of Information Technology Services and CIO at St. Thomas University. The impact of a digital charisma of a student enables us to increase the quality of education and the proportion of students who have completed their studies from 20 to $60 \%$ successfully (Rudich, 2020).

Modern education receives a strong boost under the influence of digitalization to enhance its contents, forms, processes, and technologies. This fact helps to reflect upon the teachers' role, in which the activity of the students is independent, initiative-built, creative and to adopt a high level of information that reflects the needs, interests, styles, and strategies of the subject (Budur et al., 2018). Relocation networks form independent, distant learning makes it difficult for the person to get academic achievement and overcome physical, space, and time constraints (Basl, 2017).

Digital technology is no longer just an additional tool, but also an obligation, need, and precondition for a modern person's existence. It directly affects higher education which is currently under reconstruction and is an important element of those processes, based on Bologna's applications and skill-based approaches in education. The concept of skills penetrates different areas of society, from elementary and secondary education through higher education, work, and employment. The development of learning skills is considered the main objective and at the same time an evaluation of the quality and education level in students. Individual skills that include creativity are an integral part of professionalism (Demir \& Budur, 2019; Doucek \& Hološka, 2019).

\section{Role of Blockchain Technology in Education}

The education sector is confronted by the challenges it has been facing for years. This includes inadequate document-based record-keeping procedures, lack of accountability inadequate training of students and teachers, no real incentive for students to learn and do well in class, and the lack of confidence in education and academic achievement due to counterfeiting. Blockchain can improve learning by providing tangible solutions to these problems (Team, 2021).

The blockchain technology introduced in 2008 and originally used for crypto-monetary transactions is currently commonly used in numerous non-financial activities. However, blockchain technology is only being used in education in the early stages; just a small number of academic institutions now apply it. At the very same time, this technique has excellent potential in the field of higher education as per the different research findings by different researchers.

The smart classroom is not very distant if it is integrated with blockchain technologies. These technologies will soon become a key part of academies all over the world. The question is, how will both employers and academicians benefit from the system? The answer recognizing that this technology is having a full 
impact on the educational sector or that it has an impact on teachers and students, it is useful to know how others have been able to use this for mechanisms improvement and, also, how Academic institutions could one day follow its lead (Song, et al., 2018).

Blockchain has several implementations in higher education, but still, this technology has not reached public awareness. Like there is no shortage of start-ups and key figures to make it feasible. However, some blockchain cases that are often used worldwide in the education system exist. The important part of our lives is learning. This is also the foundation for technology development. The Blockchain is the element of innovation from which schools can greatly benefit. The concept of smart device technology offers most of the teaching opportunities.

Based on its features and applications in educational contexts, Blockchain technology was identified. For example, the innovation on the platform created with blockchain technology called EduCTX was defined in the most cited studios. It provides a globally trusted, decentralized network of credit transfer and graduation for students and higher schools (HEIs), such as other potential stakeholders, like industries, organizations, and institutions globally (Turkanovic et al., 2018).

Blockchain technology will benefit from building a trustable education credit and grading blueprint. Concept evidence is introduced using the open-source Ark blockchain blueprint. This addresses students and educational institutions from a homogenous global perspective. Learners can take advantage of a single or transparent view of the finished classes, whilst the model can access the most advanced information regardless of the learner's academic background. The proposed amendment receives many potential employers who are instantly able to validate the details of the student. The implementation of this solution focuses on the decentralized network mechanism peer-to-peer. This truly exchanges the system of higher education grading for an efficient, streamlined, omnipresent model based on the blockchain of current world-class documentation. This process ultimately adapts to an overall credit and grading system for higher education that is consistent, streamlined, and worldwide.

In 2040, technology blockchain will play a significant role in accrediting students' competencies and universities. Learning directions in the blockchain will be protected and verified by coworkers and universities. Certifaction.io is a Swiss start-up company that collaborates with many universities, corporations, and SWITCH, "the Swiss national research and education network organization". An institution gives the students a degree and notifies the firm. The company states this achievement into a blockchain that is available and checks the accuracy and creates university accreditation documentation. This information is shared with the student by the institution. The authenticity of a grade can be approved only by a future employer using the blockchain node (Komer, 2021).

\section{Future of Education}

Because education needs to be approached more individually, homeschooling will be given priority. Students can learn and study whenever they want and for as long as they want. The study incorporates multiple perspectives and virtual reality. New e-learning platforms offer students opportunities for on-line discussion and discussion of issues. This is the correct way to learn online. A physical school isn't going to be restricted to learning. A new facility will be the traveling classroom and the modern world. Games 
that help children to code, toys that instruct robotics, and different teacher applications to provide students with information will become normal. Teaching and learning processes will be supported by technologies. Learning will become more practical and innovative. Students will be examined for skills that are critical and solve problems (NerdyMates.com).

New forms of student-oriented collaboration and mentoring will require students to take more responsibility for the performance of their education. The value of teachers as "knowledge broadcasters" will decline in the framework of digital technology education and their significance will grow as people who accompany personal student learning. Such alterations in academic formats will require teachers and those associated with digital technologies to make new specialized skills.

Digital courses including the use of artificial intelligence to better modify the student experience make curricula much more compatible in design, making routes to achieve certification more flexible and in which timescales. AI teachers can aggregate student 'learning data' and improve the focus on teaching, the grouping of students, and delivery accuracy based on how exactly everyone understands their course work (Johnes, 2020).

We must always keep in mind that the skills and competencies acquired throughout all higher education institutions and programs, with significant assistance from e-communication and learning, and organized by trained academics and trainers, will qualify you as an educated adult, ready to participate actively in society. Albert Einstein once said, "Education is what remains after one has forgotten all he learned in school, all the skills you accumulate inside a functioning university campus which, in the twenty-first century, will become Digital" (Einstein).

\section{Conclusion}

While e-learning is not a new concept, COVID-19 has brought new elements to the table. We live in a time where emerging digital technologies are more concentrated than ever in all aspects of our lives. These developments have already begun to influence the activities of universities. However, to reap the benefits of digitization and provide students with more resources, educational institutions must undergo major transformations. The evolution of digital education in various universities should be in line with the unique characteristics of each university and its students. Furthermore, it is important to note that the advancement in digital education would reinforce the pattern of university differentiation and specialization.

Technology in the twenty-first century is enhancing the education sector, and these innovations must be implemented in the educational system. Higher educational institutions should offer standardized and quality education to meet the current labor market demands, which would possibly necessitate a revision of the student curriculum and a decrease in study hours in applied disciplines. Simultaneously, students can learn the fundamentals of conceptual design and entrepreneurship, and also behavioral patterns skills, to train them for independent work as micro-entrepreneurs in the innovation economy. The ability to ensure that each individual acquires new skills and understanding at any level of professional growth is an undeniable benefit of digital technology, which is critical in a rapidly changing world.

More complex than technology and moving online, the digital university is about the ability to adapt, investment, creativity, imagination, and collaboration. An investment in the Digital Education strategy, as 
a technologically advanced viewpoint in higher education, seems more than welcome to assist the total economy is growing stably and sustainably. Digital education is an institutional education model that allows students to access learning, study, business meetings, and administrative data an time and from any place. In the real world, universities' ability to provide access to education in response to changing behavior, requirements, and circumstances is a priority. The Digital Education Model is a comprehensive experience, but it also portrays a way for academic institutions to adapt to 21 st-century society's evolving needs while maintaining relevance and ensuring learning and teaching quality. Investing in education ensures our safety in the future.

\section{References}

Basl, J. (2017). Penetration of industry 4.0 principles into ERP vendors' products and services - A central european study. Proceedings of the International Conference on Research and Practical Issues of Enterprise Information Systems.

Budur, T., Demir, A., \& Cura, F. (2021). University Readiness to Online Education during Covid-19 Pandemic. International Journal of Social Sciences and Educational Studies, 8(1), 180-200.

Budur, T., Rashid, C. A., \& Poturak, M. (2018). Students' perceptions on university selection, decision making process: A case study in Kurdistan Region of Iraq. International Journal of Social Sciences \& Educational Studies, 5(1), 133-144.

Clark, R. C., \& Mayer, R. E. (2003). E-learning and the science of instruction: Proven guidelines for consumers and designers of multimedia learning. San Francisco: CA, John Wiley \& Sons, Inc.

Demir, A., \& Budur, T. (2019). Roles of leadership styles in corporate social responsibility to nongovernmental organizations (NGOs). International Journal of Social Sciences \& Educational Studies, 5(4), 174-183.

Doucek, P., \& Hološka, J. (2019). Digital economy and industry 4.0 IDIMT2019. Innovation and Transformation in a Digital World, 27th Interdisciplinary Information Management Talks (Sept. 4-6, 2019 Kutná Hora, Czech Republic), TRAUNER Druck GmbH and Co KG, Linz, 2019.

Dzhavdatovna, A. Z., \& Azimovich, K. B. (2020). Development of higher education systems on the basis of digitization and clustering. Academy, (8 (59).

Faccia, A., Moşteanu, N.R., Fahed, M., \& Capitanio, F. (2019). Accounting information systems and ERP in the UAE. In Proceedings of 3rd International Conference on Cloud and Big Data Computing, 90- 94.

Goyal, S. (2012). E-Learning: Future of education. Journal of Education and Learning, 6(4), 239-242.

Huang, R. H., Liu, D. J., Tlili, A., Yang, J. F., \& Wang, H. H. (2020). Handbook on facilitating flexible learning during educational disruption: The Chinese experience in maintaining undisrupted learning in COVID-19 Outbreak. Beijing: Smart Learning Institute of Beijing Normal University.

Jones, N. (2020, July 02). Digital hybrids: The future of higher education. Retrieved March 24, 2021, from https://www.dailycsr.com/Digital-hybrids-the-future-of-higher-education_a1796.html

Kannadhasan, S., Shanmuganantham, M., Nagarajan, R., \& Deepa, S. (2020). The Role of Future ELearning System and Higher Education. International Journal of Advanced Research in Science, Communication, and Technology (IJARSCT).

Kargic L., \& Poturak M. (2014), Factors That Influence State or Private University Selection. European Journal of Contemporary Education, 9(3).

Korner, T. (2021). Learning in 2040. Eleed, 14(1). 
Mohammed, K. S., Rashid, C. A., Salih, H. A., \& Budur, T. (2020). The Role of Online Teaching Tools on the Perception of the Students during the Lockdown of Covid-19. International Journal of Social Sciences \& Educational Studies, 7(3), 178-190.

Moşteanu, N.R., Faccia, A., Cavaliere, L.P., \& Bhatia, S. (2020). Digital technologies' implementation within financial and banking system during socio distancing restrictions - back to the future. International Journal of Advanced Research in Engineering and Technology, 11(6), 307-315

NerdyMates.com. Glimpse at how education will possibly look like in 2050. Retrieved March 24, 2021, from https://nerdymates.com/blog/education-future

New perspectives on education's digital future. (2020, December 16). Retrieved March 25, 2021, from https://news.microsoft.com/en-gb/2020/12/16/new-perspectives-on-educations-digital-future/

Ngai, E., Poon, J., \& Chan, Y. (2007). Empirical examination of the adoption of WebCT using TAM. Computers \& Education, 48, 250-267.

Norman, D. V., Martha, C. I., \& Randy, G. (2013). Teaching in blended learning environments: Creating and sustaining communities of inquiry. AU Press, Canada.

Pappas, C. (2020, November 17). Top 10 e-Learning statistics for 2014 you need to know. Retrieved March 24, 2021, from https://elearningindustry.com/top-10-e-learning-statistics-for-2014-youneed-to-know

Poturak, M. (2014). Private universities service quality and student's satisfaction. Global Business and Economics Research Journal, 3(2), 33-49.

Reed, D (2021, January 21). Is online learning the future of higher education? Retrieved March 24, 2021, from https://studybreaks.com/thoughts/online-learning-higher-education/

Rudich, K. (2020). Ed Clark, University of St. Thomas: Present-Day young people have already obtained a digital personality in addition to their real one. Retrieved March 23, 2021 from https://hightech.fm/2020/01/20/ed-clark

Song, J., Demir, M., Prevost, J., \& Rad, P. (2018). Blockchain Design for Trusted Decentralized IoT Networks. 13th Annual Conference on System of Systems Engineering (SoSE), IEEE, 2018

Spies, M., \& Brothers, P. (2020). Education in 2030. Five Scenarios for the Future of Learning and Talent [report] Holoniq.com Retrieved March 24, 2021, from https://www.holoniq.com/wpcontent/uploads/2020/01/HolonIQ-Education-in-2030.pdf

Team, P. (2021, January 13). Blockchain education applications \& use cases. Retrieved March 23, 2021, from https://pixelplex.io/blog/blockchain-education-use-cases-and-applications/

Turkanović, M., Hölbl, M., Košič, K., Heričko, M., \& Kamišalić, A. (2018). EduCTX: A blockchainbased higher education credit platform. IEEE access, 6, 5112-5127.

UNESCO (2020). 290 million Students out of school due to COVID-19: UNESCO releases first global numbers and mobilizes response. UNESCO. 